\title{
Cost of Cystic Fibrosis: Analysis of Treatment Costs in a Specialized Center in Northern Italy
}

\author{
Carla Colombo · Valeria Daccò · Gianfranco Alicandro · Silvana Loi · Silvio Mazzi · Carlo Lucioni · \\ Roberto Ravasio
}

To view enhanced content go to www.advancesintherapy.com

Received: January 8, 2013 / Published online: February 7, 2013

(c) The Author(s) 2013. This article is published with open access at Springerlink.com

\section{ABSTRACT}

Introduction: Advances in cystic fibrosis (CF) therapy have resulted in improved survival and increasing treatment burden and costs. The economic impact of current treatment strategies for CF is poorly defined.

Methods: The authors prospectively assessed direct medical costs (including hospitalizations, outpatient interventions, drugs, devices, dietetic products) in 165 consecutive CF patients (aged 5-39 years) seen between March and July 2009.

Results: The mean annual cost/patient increased with age and lung disease severity from

C. Colombo · V. Daccò · G. Alicandro $\cdot$ S. Loi Cystic Fibrosis Centre - Fondazione IRCCS, Ca' Granda, Ospedale Maggiore Policlinico, University of Milan, Milan, Italy

S. Mazzi · C Lucioni · R. Ravasio $(\varangle)$

Springer Healthcare Italia srl, Via Lanino 5 - 20144

Milan, Italy

e-mail: Roberto.Ravasio@springer.com

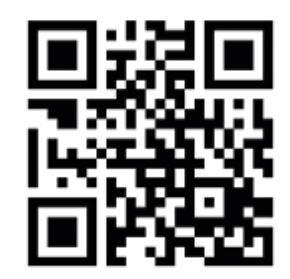

Enhanced content for Advances in Therapy articles is available on the journal web site: www.advancesintherapy.com
$€ 4,164$ in children aged $\leq 5$ years to $€ 30,123$ in patients aged $>5$ years with severe lung disease (forced expiratory volume in 1 second $\left[\mathrm{FEV}_{1}\right]<40 \%$ of predicted). The increase in costs involved all items, with a progressive increase in cost attributed to hospitalizations.

Conclusion: Treatment of CF is associated with relevant cost for the Italian National Healthcare Service. Costs of illness tend to increase progressively with age, suggesting that increasing economic resources should be allocated to the treatment of $\mathrm{CF}$, given the increasing number of patients surviving into adulthood.

Keywords: Cystic fibrosis; Forced expiratory volume; Healthcare costs; Lung disease; Respiratory

\section{INTRODUCTION}

Cystic fibrosis (CF) is one of the most prevalent severe genetic diseases, with a high economic impact on healthcare systems due to its complexity [1]. The results of literature reviews, surveys, and registry analyses show a mean prevalence of $0.737 / 10,000$ citizens in the $27 \mathrm{EU}$ countries [2]. This prevalence is similar to the value of $0.680 / 10,000$ citizens in Italy [3]. 
CF is caused by a lack or dysfunction of cystic fibrosis transmembrane regulator (CFTR) protein, which acts mainly as a chloride channel at the apical membrane of epithelial cells, with consequent alteration of electrolyte transport, production of abnormally thick secretions, and progressive organ damage [4]. The clinical picture of CF is highly variable in terms of organ involvement (sweat glands, airways, pancreas, liver, gut, deferent ducts), age at diagnosis, and development of complications [5]. Lung disease is observed in over $90 \%$ of patients and represents the leading cause of morbidity and mortality [6].

Since its first description in 1938, CF has progressively evolved from a disease leading to death at a very young age due to respiratory failure and malnutrition, to a chronic condition with different manifestations also affecting adults [7].

Over the last 20 years, the therapeutic approach has markedly improved with the availability of new therapies for the prevention and treatment of respiratory infections (mucus active drugs, antibiotics) and closer attention to nutritional status and to complications associated with the disease (e.g., diabetes, liver disease, osteoporosis). While in the past antibiotics were mostly used to treat the exacerbations of CF-associated lung disease. More recently, the chronic use of antibiotics administered in aerosol formulation to suppress lung infection has become common practice in the routine care of CF and is strongly recommended by current CF therapeutic guidelines $[8,9]$.

The marked improvement in the therapeutic approach for CF has been paralleled by a progressive increase in mean life expectancy, which is now nearly 40 years in Western countries [10], with a consequential increase in the number of adult patients [11] who often have a more complex and severe form of the disease.
Advances in therapy have been incremental and have resulted in an increase in direct medical costs and treatment burden [12].

Several studies designed to assess the costs of illness in patients with CF were carried out more than two decades ago [13-21]. These studies were reviewed by Krauth et al. [1] who highlighted the wide range of mean annual cost per patient (US\$6,200-16,300, 1996 rate), mainly due to differences in the clinical conditions of the patients considered, healthcare systems involved, and in the completeness of healthcare services and resource consumed. Healthcare costs were directly related to age and severity of the disease [1]. Most of these studies had major limitations, including the fact that only five were based on individual patient care data $[14,16,18-20]$, whereas three were only aggregated expert cost estimations.

More recently, Briesacher et al. [22] examined patterns of treatment in relation to whole costs using a nationwide research database of the healthcare claims of privately insured CF patients in the period 2001-2007 [22]. This study documented a progressive increase in costs, from US $\$ 18,715$ in 2001 to US\$29,718 in 2007 (+61\%). This was largely influenced by more intensive monitoring of clinical status and lung function as well as by the increasing prevalence of respiratory pathogens (only $1.2 \%$ of the patients colonized by Pseudomonas aeruginosa in 2001, compared with $63.2 \%$ in 2007), as indicated by the sharp increase in the use of oral (from $54.1 \%$ to $71.8 \%$ ) and inhaled antibiotics (from $25.7 \%$ to $39.3 \%$ ). Analysis by age confirmed the marked increase in costs of care for patients aged $<10$ years (from US $\$ 3,060$ to US $\$ 31,722$ ) and for older patients, which more than doubled over the same period.

As no study has been conducted in Italy, the aim of this economic evaluation was to 
estimate the mean annual costs associated with the treatment of CF patients for the Italian National Healthcare Service (NHS). The authors therefore conducted a prospective, monocentric study to assess direct medical costs associated with CF treatment in Italy. All other costs (e.g., productivity losses, informal care, out-of-pocket expenses, etc) were not considered.

\section{MATERIALS AND METHODS}

\section{Study Design}

The authors carried out an observational, prospective, monocentric, prevalence-based study with a bottom-up design (consumption/ cost data of individual patients were determined and costs were aggregated over groups to arrive at total disease costs) [23].

The healthcare resources used by a sample of CF patients followed at the Lombardia Regional Cystic Fibrosis Reference Center (CFRRC) in Milan, Italy were assessed. All consecutive patients seen during an outpatient visit or who were hospitalized between March and July 2009 were asked to participate in the study.

Demographic and clinical data were recorded at baseline using a dedicated case report form (CRF). Data concerning the use of healthcare resources were collected in the CRF at each access to the CFRRC. Each patient was prospectively followed for 12 months. The number of hospitalizations and the length of stay were collected for each patient. For each drug, the dosage prescribed and the number of days on treatment per year for each patient was recorded. Single drugs were clustered into therapeutic groups. The type and number of each outpatient medical intervention, device, and dietetic product was recorded.

Enrolled patients were divided into two subgroups: Group 1 included patients 5 years of age or less ( $\leq 5$ years) and Group 2 included patients more than 5 years of age ( $>5$ years). At enrollment, patients in Group 2 were stratified according to severity of lung disease, based on forced expiratory volume in 1 second $\left(\mathrm{FEV}_{1}\right)$ values: mild ( $\mathrm{FEV}_{1} \geq 70 \%$ of predicted), moderate $\left(\mathrm{FEV}_{1} \geq 40-<70 \%\right)$ and severe $\left(\mathrm{FEV}_{1}<40 \%\right)$ [9]. In addition, the probability of 5-year survival was calculated for each patient in Group 2, according to the model proposed by Liou et al. [24, 25]. For this purpose, all variables included in the model were recorded in the CRF (age, gender, $\mathrm{FEV}_{1} \%$, weight Z-score, pancreatic status, diabetes, Staphylococcus aureus infection, Burkholderia cepacia complex infection, number of pulmonary exacerbations/year). Patients in Group 1 were not stratified for for lung disease severity, as reliable testing of respiratory function is not possible in children aged $\leq 5$ years and there is no validated algorithm to estimate disease severity in this age group.

\section{Annual Cost Analysis}

The mean annual treatment cost was based on the overall healthcare resources (direct medical costs) used for each patient and reimbursed by the Italian NHS. Drug costs were obtained by the actual price paid by the Italian NHS, whereas hospitalization costs and costs associated with outpatient medical interventions were calculated according to reimbursement tariffs applied in Italy (reimbursed by Italian NHS). All costs denote 2009 prices.

A mean single annual cost was calculated for patients in Group 1. For patients in Group 2, three mean annual costs were calculated according to the lung disease severity class; a single mean annual cost was also estimated, adjusted for the actual distribution of the total number of patients followed-up at the CFRRC in each class of disease severity. 


\section{Statistical Analysis}

Continuous data were expressed as means \pm standard deviations or medians with ranges according to the distribution of the variables. Categorical data were expressed as numbers and percentages. The significance of the differences between groups was evaluated by the MannWhitney test or the Kruskal-Wallis test (twotailed). A $P$ value of $<0.05$ was considered statistically significant. All analyses were conducted using Microsoft ${ }^{\circledR}$ Excel $^{\circledR}$ for Windows ${ }^{\circledR}$ (Microsoft Corporation, Seattle, WA, USA) and SPSS $^{\circledR}$ version 13.0 (SPSS Inc, Chicago, IL, USA).

\section{RESULTS}

\section{Patient Demographics and Disease Severity at Enrollment}

A total of 161 CF patients were enrolled; 55 consecutive patients aged $\leq 5$ years (Group 1) and 106 consecutive patients aged $>5$ years (Group 2). This number of patients represents approximately $30 \%$ of the CF population attending the CRRFC. Median age of the population enrolled was 11.6 years, with $25 \%$ adults.

Table 1 summarizes the main demographics and clinical characteristics for each group.

Pancreatic insufficiency was present in $72.7 \%$ of patients, and chronic $P$. aeruginosa infection was present in $9 \%$ of patients in Group 1 and in $36 \%$ of those in Group 2.

In Group 2, a positive correlation between age and lung disease severity was documented (Fig. 1). Table 2 shows the distribution of patients in Group 2 by disease severity and the corresponding probability of 5-year survival that were inversely correlated. The difference in the probability of survival across severity groups was statistically significant $(P<0.001)$.
Table 1 Patient demographics and clinical characteristics

\begin{tabular}{lll}
\hline & $\begin{array}{l}\text { Group 1 } \\
(\leq 5 \text { years }) \\
(n=55)\end{array}$ & $\begin{array}{l}\text { Group 2 } \\
(>5 \text { years }) \\
(n=106)\end{array}$ \\
\hline $\begin{array}{ll}\text { Male, } n(\%) \\
\text { Age (years) }\end{array} \quad 25(45)$ & $58(55)$ \\
$\quad$ Mean age \pm SD & $3 \pm 2$ & $17 \pm 8$ \\
$\quad$ Median age & 2.8 & 16.3 \\
$\quad$ Range & $0-5$ & $5-39$ \\
Adults, $n$ (\%) & & $40(37)$ \\
Pancreatic insufficiency, $n(\%)$ & $31(56)$ & $86(81)$ \\
Diabetes, $n$ (\%) & 0 & $20(19)$ \\
Age at diagnosis (months) & & \\
$\quad$ Median & 0.2 & 2.5 \\
$\quad$ Range & $0-59$ & $0-283$ \\
Pseudomonas aeruginosa & & \\
$\quad$ At least one positive culture & $18(33)$ & $59(56)$ \\
$\quad$ Chronic infection & $5(9)$ & $38(36)$ \\
Other gram-bacteria & 0 & $14(13)$ \\
\hline
\end{tabular}

$S D$ standard deviation

${ }^{a}$ At least one positive culture for Burkholderia cepacia complex or Alcaligenes xylosoxidans

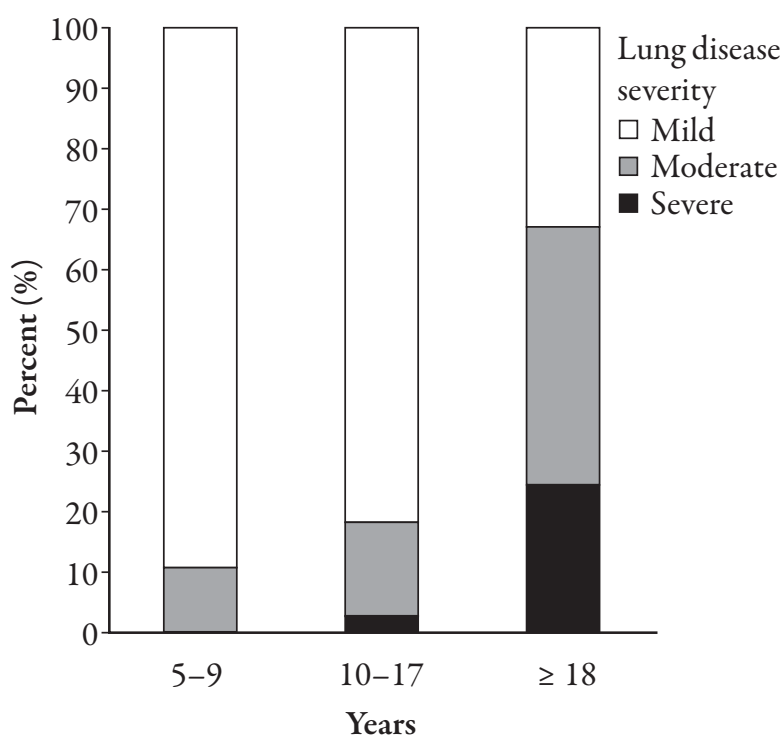

Age categories in Group 2

Fig. 1 Lung disease severity (mild $\left[\mathrm{FEV}_{1} \geq 70 \%\right.$ of predicted], moderate $\left[\mathrm{FEV}_{1} \leq 40-<70 \%\right]$, and severe $\left[\mathrm{FEV}_{1}<40 \%\right]$ ) by age categories in Group 2. FEV forced expiratory volume at 1 second 
Table 2 Probability of 5-year survival in cystic fibrosis patients included in Group 2, stratified by severity of lung disease

\begin{tabular}{lll}
\hline Class of severity & $N(\%)$ & $\begin{array}{l}\text { Probability } \\
\text { of 5-year } \\
\text { survival }\end{array}$ \\
& & (mean \pm SD) \\
\hline Mild $\left(\mathrm{FEV}_{1} \geq 70 \%\right)$ & $64(61)$ & $98 \pm 3$ \\
Moderate $\left(\mathrm{FEV}_{1} \leq 40-<70 \%\right)$ & $29(27)$ & $87 \pm 10$ \\
Severe $\left(\mathrm{FEV}_{1}<40 \%\right)$ & $13(12)$ & $57 \pm 28$ \\
Total $_{P \text { value }}^{\mathrm{b}}$ & $106(100)$ & $90 \pm 17$ \\
\hline
\end{tabular}

$F E V_{1}$ forced expiratory volume in 1 second

${ }^{a}$ According to the Liou model [24]

${ }^{\mathrm{b}}$ Kruskal-Wallis test

\section{Utilization of Healthcare Resources}

Table 3 shows healthcare resources per patient used during the follow-up period. The mean number of medical interventions/patient/ year and the mean number and duration of hospitalizations/patient/year increased with age and disease severity. The mean number of hospitalizations/year/patient increased approximately ninefold in patients of Group 2 with severe disease compared with those of Group $1(P<0.001)$ and a significantly longer duration of hospitalization was also documented $(P<0.001)$ (Table 3).

Mean days on treatment/year/patient for different drug categories are shown in Table 3.

Of note, the number of days on antibiotic treatment (by any route of administration) increased significantly with age and lung disease severity $(P<0.001)$.

Table 3 Utilization of healthcare resources

\begin{tabular}{|c|c|c|c|c|c|}
\hline & $\begin{array}{l}\text { Group } 1 \\
(n=55)\end{array}$ & $\begin{array}{l}\text { Group } 2-\text { mild } \\
(n=64)\end{array}$ & $\begin{array}{l}\text { Group } 2 \text { - moderate } \\
(n=29)\end{array}$ & $\begin{array}{l}\text { Group } 2 \text { - severe } \\
(n=13)\end{array}$ & $P$ value $^{\mathrm{a}}$ \\
\hline $\begin{array}{l}\text { Mean number of outpatient } \\
\text { medical interventions/year/patient }\end{array}$ & 26 & 27 & 34 & 36 & 0.002 \\
\hline $\begin{array}{l}\text { Mean number of hospitalizations/ } \\
\text { year/patient }\end{array}$ & 0.2 & 0.4 & 1.01 & 1.08 & $<0.001$ \\
\hline $\begin{array}{l}\text { Mean duration of hospitalization } \\
\text { (days)/year/patient }\end{array}$ & 3 & 5 & 14 & 32 & $<0.001$ \\
\hline \multicolumn{6}{|c|}{ Mean days on treatment/year/patient } \\
\hline Intravenous antibiotics & 17 & 25 & 60 & 117 & 0.001 \\
\hline Inhaled antibiotics & 38 & 133 & 208 & 311 & $<0.001$ \\
\hline Oral antibiotics & 20 & 76 & 179 & 240 & $<0.001$ \\
\hline Bronchodilators & 365 & 359 & 365 & 365 & NS \\
\hline Mucus active drugs & 15 & 103 & 94 & 112 & 0.015 \\
\hline Vitamins & 365 & 365 & 365 & 365 & NS \\
\hline Pancreatic enzymes & 212 & 257 & 340 & 337 & 0.003 \\
\hline Antacids & 86 & 88 & 142 & 84 & NS \\
\hline Bile acids & 56 & 51 & 63 & 28 & NS \\
\hline Prokinetic agents & 17 & 11 & 13 & 5 & NS \\
\hline Insulin & - & 15 & 31 & 135 & 0.001 \\
\hline
\end{tabular}

$N S$ not significant

${ }^{a}$ Kruskal-Wallis Test 


\section{Annual Cost of Treatment}

The mean annual cost per patient increased with age and disease severity, with values ranging from $€ 4,164$ in Group 1 to $€ 30,123$ in Group 2 with severe disease (Table 4). This increase in costs involved all items. The relative contribution of hospitalizations on the overall costs increased with severity of lung disease (Fig. 2). All differences in cost, between the two age groups and the subgroups with different disease severities, were statistically significant, with the only exception of costs related to devices, which was not significant (Table 4).

Table 5 shows the relative contribution of each drug category to the overall cost of drugs administered over the follow-up period. Inhaled antibiotics and mucus active drugs were the major drug categories affecting annual drug cost. The relative contribution of i.v. antibiotics and oral antimycotics on overall annual drug costs increased with age and disease severity, and was accompanied by a decrease in the relative contribution of bronchodilators, pancreatic enzymes, vitamins, and antacids (from $42.7 \%$ in
Group 1 to $12.6 \%$ in Group 2 with severe lung disease).

Since patients with severe lung disease were more likely to be enrolled, due to a higher likelihood of access to the CFRRC compared with those with milder lung disease, we estimated a single mean annual cost for Group 2, adjusting for the actual distribution of all patients aged $>5$ years followed-up at the CRRFC ( $n=338)$ in each class of disease severity. Actually, the frequency of severe lung disease was higher among the 106 patients enrolled in Group $2(12.3 \%)$ than in all patients aged $>5$ years followed at our center (8.6\%). A mean annual cost per patient in Group 2 was estimated at $€ 15,137$, which is more than three times the cost for patients of Group $1(€ 4,164, P<0.0001$ - Mann-Whitney Test).

Finally, the mean annual cost for adult patients ( $\geq 18$ years) was 1.7 times higher than the cost for patients aged 5-18 years $(€ 20,931 \pm$ $€ 14,903$ vs. $€ 12,378 \pm € 11,277, P=0.004$ MannWhitney Test) and five times higher than for patients $\leq 5$ years $(€ 4,164 \pm € 4,065, P<0.0001$ Mann-Whitney Test).

Table 4 Mean annual cost (in Euro $[€]$ ) per patient stratified by age and disease severity

\begin{tabular}{|c|c|c|c|c|c|c|}
\hline & \multicolumn{6}{|c|}{ Mean annual cost } \\
\hline & Total & Drugs & $\begin{array}{l}\text { Outpatient } \\
\text { medical } \\
\text { interventions }\end{array}$ & Hospitalizations ${ }^{a}$ & Devices & $\begin{array}{l}\text { Dietetic } \\
\text { product }\end{array}$ \\
\hline $\begin{array}{l}\text { Group 1 } \\
(n=55)\end{array}$ & 4,164 & 2,704 & 728 & 524 & 164 & 44 \\
\hline $\begin{array}{l}\text { Group } 2-\text { mild } \\
(n=64)\end{array}$ & 12,186 & 9,625 & 797 & 1,495 & 168 & 102 \\
\hline $\begin{array}{l}\text { Group } 2 \text { - moderate } \\
(n=29)\end{array}$ & 19,300 & 13,996 & 1,045 & 3,886 & 144 & 229 \\
\hline $\begin{array}{l}\text { Group 2 - severe } \\
(n=13)\end{array}$ & 30,123 & 19,625 & 1,158 & 8,793 & 312 & 236 \\
\hline$P$ value $^{\mathrm{b}}$ & $<0.001$ & $<0.001$ & 0.002 & $<0.001$ & 0.07 & 0.039 \\
\hline
\end{tabular}

${ }^{a}$ Including costs for inpatient admissions and for day hospital

${ }^{\mathrm{b}}$ Kruskal-Wallis test 


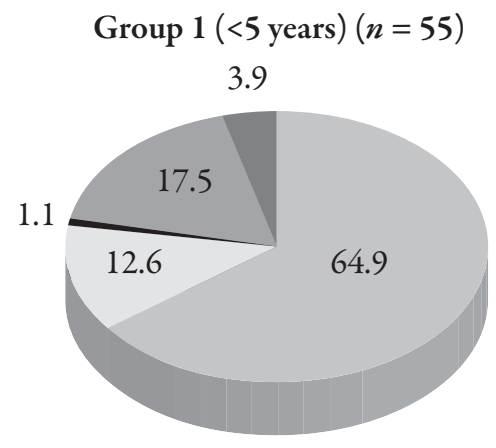

Group 2 - moderate $(n=29)$

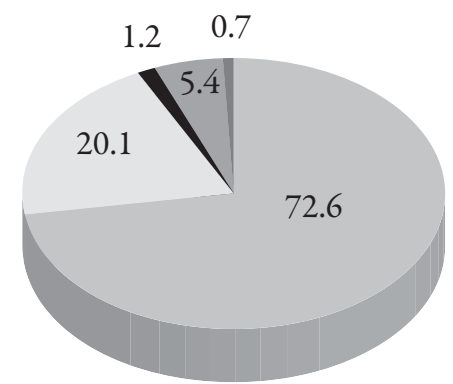

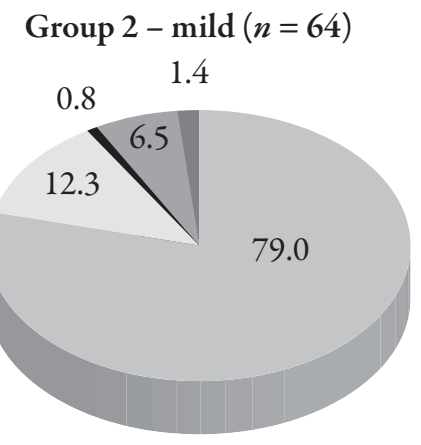

Group 2 - severe $(n=13)$

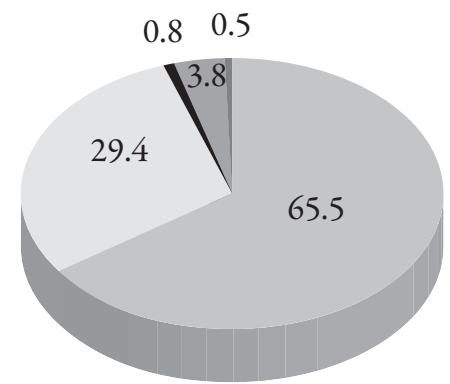

Drugs

Hospitalization

Dietetic products

Outpatients medical interventions

Devices

Fig. 2 Relative contribution of different items of health cost stratified by age and lung disease severity

\section{DISCUSSION}

In this prospective observational study, the cost analysis was based on individual patient care data from a population of $161 \mathrm{CF}$ patients who were seen consecutively between March 2009 and July
2009 at the CFRRC in Milan, Italy. According to a specific regulation in force in Italy [26], CF patients are followed in reference centers and all drugs must prescribed by the reference center. This system greatly favored a reliable monitoring of drug utilization in our study.

Table 5 Relative contribution of each drug category to the overall annual cost of drugs ${ }^{\mathrm{a}}$

\begin{tabular}{lllll}
\hline & $\begin{array}{l}\text { Group 1 } \\
(n=55)\end{array}$ & $\begin{array}{l}\text { Group 2 - mild } \\
(n=64)\end{array}$ & $\begin{array}{l}\text { Group 2 - moderate } \\
(n=29)\end{array}$ & $\begin{array}{l}\text { Group 2 - severe } \\
(n=13)\end{array}$ \\
\hline Bronchodilators & 16.6 & 4.6 & 3.2 & 2.3 \\
Intravenous antibiotics & 1.3 & 3.0 & 11.2 & 22.0 \\
Oral antibiotics & 1.2 & 1.8 & 2.0 & 2.6 \\
Inhaled antibiotics & 25.7 & 25.4 & 27.7 & 22.7 \\
Mucus active drugs & 24.8 & 46.3 & 29.2 & 24.8 \\
Vitamins & 5.4 & 1.6 & 1.2 & 0.8 \\
Pancreatic enzymes & 18.4 & 11.9 & 10.8 & 9.0 \\
Antacids & 2.3 & 0.8 & 0.9 & 0.5 \\
Bile acids & 1.9 & 0.5 & 0.4 & 0.1 \\
Prokinetic agents & 0.1 & 0.1 & 0 & 0 \\
Oral antimycotic & 0 & 1.8 & 9.6 & 12.2 \\
Insulin & 0 & 1.0 & 1.2 & 2.1 \\
\hline
\end{tabular}

${ }^{\text {a }}$ Results are presented as percentage of total annual cost of drugs 
Only direct medical costs were considered, including inpatient and outpatient costs and costs associated with drugs, dietetic products, and device prescriptions. The Italian NHS perspective was considered.

The results of this study clearly show that mean treatment costs increase with disease severity, assessed by $\mathrm{FEV}_{1}$ categories and confirmed by the Liou 5-year survival model [24]. Treating a patient with severe lung disease costs about 2.5 times the costs of treating a patient with mild disease $(€ 30,123$ vs. $€ 12,186)(P<$ $0.001)$; this increase was determined mainly by hospitalization $(+488 \%)$, followed by drugs $(+104 \%)$, and outpatient medical interventions $(+45 \%)$. Similar findings were previously reported by Lieu et al. [20] who also classified disease severity according to $\mathrm{FEV}_{1}$ values. These data confirm the importance of disease severity as a cost driver.

The results also demonstrate a direct correlation between treatment cost and age; the ratio between the mean cost of illness for adults and children was 3.4 in the current study, which is higher than previously reported (2.0-2.3) [14, 27]. It cannot be excluded that the lower economic resources spent for pediatric patients may be attributed to the aggressive therapeutic approach, which is now recommended beginning at the time of diagnosis and is associated with slower progression of lung disease and a reduced number of hospitalizations in childhood [28].

Indeed, the cost for hospitalization was 17-fold higher in patients in Group 2 with severe lung disease compared with patients in Group 1.

The direct medical costs of illness estimated in the present study are slightly lower than those reported in two recent studies. In a multicenter study involving seven CF centers in Germany, Eidt-Koch et al. [29] analyzed the cost of pharmacological therapy in 301 patients with a mean age of 19.9 years. In this study, the mean annual cost per patient was $€ 21,603$. Medication costs were higher in older patients, probably due to the higher rate of bacterial colonization in adults than in children (up to $95 \%$ vs. $67.4 \%$ of patients aged $<17$ years). The lower costs of illness found in this study may be related to the much lower rate of gram-negative chronic lung infection seen in our population $(26.7 \%)$. In addition, drug costs in Germany are generally higher than in Italy. For aerolized antibiotics, the cost for tobramycin during the study period was $€ 59.16 /$ unit in Germany compared with $€ 50 /$ unit in Italy; colistin, the most frequently prescribed antibiotic for inhalation in our patients (86\%), was €17.47/unit in Germany, which is around three times more expensive than in Italy. Most of the other CF-related therapies (pancreatin, azithromycin, itraconazol) were twice as expensive in Germany.

Another observational, prospective study analyzed the cost of illness in 352 patients (mean age 14.6 years) with mild lung disease from 61 US centers during a 48-week clinical trial (TIGER-1) investigating the efficacy of denufosol versus placebo [30]. The mean cost per patient due to hospitalization was US\$4,367, and the cost due to pharmacological therapy was US $\$ 33,394$; these costs accounted for $11.3 \%$ and $86.7 \%$ of the total costs, respectively. Expressed in euros, this would correspond to $€ 29,610$ as compared to a cost of $€ 12,021$ observed in patients with mild severity of the disease. However, this study also considered the costs of healthcare providers and indirect costs (number of days missed from work or school) that were not considered in this study. In addition, despite the fact that patients in the TIGER-1 trial had a nearly normal lung function $\left(\mathrm{FEV}_{1}>75 \%\right.$ of predicted), more than one-third $(37 \%)$ were on long-term inhaled antibiotics (mostly tobramycin). This is a higher percentage when compared with patients in 
this study with the same clinical characteristics (14\%) who were mostly receiving the much cheaper colistin.

The major limitation of the current study is that it was carried out in a single center, enrolling a relatively limited sample size, with a predominance of pediatric patients (only $25 \%$ of the patients were adults) who are less frequently colonized by respiratory pathogens. This may have caused an underestimation of the mean cost per patient that may not be fully representative of the average costs sustained by CF centers in Western countries. In conclusion, the results show that the treatment of CF represents a major cost for the Italian healthcare system [1], that may increase further with the forthcoming availability of new and expensive drugs targeted to correct the basic defect underlying CF [31, 32]. Disease costs tend to increase progressively with age, suggesting that increasing economic resources should be allocated to the treatment of CF given the increasing number of patients surviving into adulthood. Despite the large economic resources necessary for providing CF patients with treatment strategies that have the potential to increase life expectancy and improve quality of life, suboptimal treatment may lead to a significant increase in costs for the healthcare system.

\section{ACKNOWLEDGMENTS}

This study was supported by a grant from Chiesi Farmaceutici S.p.A. The authors thank Dr. Roberto Buzzetti for advice concerning the design of the study. Dr. Ravasio is the guarantor for this article, and takes responsibility for the integrity of the work as a whole.

Contributors. C.C., S.M., C.L., and R.R.: substantial contributions to conception and design; SL and V.D. acquisition of data; S.M.,
C.L., R.R., and G.A.: analysis and interpretation of data; C.C., V.D., and R.R.: drafting the article; C.C. and V.D.: revising the article critically for important intellectual content; CC, VD, GA, SL, $\mathrm{SM}, \mathrm{CL}$, and RR: final approval of the version to be published.

Collaborators. Anna Brivio, Lauretta Valmarana, Rossella Valmarana, Carmen Zappa, Fondazione IRCCS, Cà Granda, Ospedale Maggiore Policlinico, Milan, Italy.

Conflict of interest. Carla Colombo declares she has no conflict of interest. Valeria Daccò declares she has no conflict of interest. Gianfranco Alicandro declares he has no conflict of interest. Silvana Loi, Silvio Mazzi, Carlo Lucioni, and Roberto Ravasio have recieved a grant from Chiesi Farmaceutici S.p.A.

Open Access. This article is distributed under the terms of the Creative Commons Attribution Noncommercial License, which permits any noncommercial use, distribution, and reproduction in any medium, provided the original author(s) and source are credited.

\section{REFERENCES}

1. Krauth C, Jalilvand N, Welte $\mathrm{T}$, et al. Cystic fibrosis cost of illness and considerations for the economic evaluation of potential therapies. Pharmacoeconomics. 2003;21:1001-24.

2. Farrell PM. The prevalence of cystic fibrosis in the European Union. J Cyst Fibros. 2008;7: 450-3.

3. Bossi A. Report 2004 del Registro Italiano Fibrosi Cistica [in Italian]. Orizzonti FC. 2006;2:4-28.

4. Flume PA, Van Devanter DR. State of progress in treating cystic fibrosis respiratory disease. BMC Med. 2012;10:88.

5. Drumm ML, Ziady AG, Davis PB. Genetic variation and clinical heterogeneity in cystic fibrosis. Annu Rev Pathol. 2012;7:267-82.

6. Davis PB. Cystic fibrosis since 1938. Am J Respir Crit Care Med. 2006;173:475-82. 
7. Davis PB. Cystic fibrosis since 1938. Am J Respir Crit Care Med. 2006;173:475-82.

8. Cohen-Cymberknoh M, Shoseyov D, Kerem E. Managing cystic fibrosis: strategies that increase life expectancy and improve quality of life. Am J Respir Crit Care Med. 2011;183:1463-71.

9. Flume PA. Chronic cystic fibrosis respiratory infections: where do we go from here? Respir Med. 2011;105(Suppl. 2):S1.

10. Patient Registry Annual Data Report 2010. Bethesda, Maryland, USA. Cystic Fibrosis Foundation website. Available at: http:// www.cff.org/UploadedFiles/LivingWithCF/ CareCenterNetwork/PatientRegistry/2010-PatientRegistry-Report.pdf. Accessed Oct 312012.

11. Mogayzel PJ Jr, Flume PA. Update in cystic fibrosis 2010. Am J Respir Crit Care Med. 2011;183:1620-4.

12. Sawicki GS, Tiddens H. Managing treatment complexity in cystic fibrosis: challenges and opportunities. Pediatr Pulmonol. 2012;47:523-33.

13. Pauly MV. The economics of cystic fibrosis. In: Lloyd-Still JD, editor. Textbook of cystic fibrosis. Boston: John Wright PSG Inc., 1983:465-76.

14. Robson M, Abbott J, Webb $\mathrm{K}$, et al. A cost description of an adult cystic fibrosis unit and cost analyses of different categories of patients. Thorax. 1992;47:684-9.

15. US Congress Office of Technology Assessment. Cystic fibrosis and DNA tests: implications of carrier screening. Washington US Government Printing Office, 1992. Available at: http://www. fas.org/ota/reports/9208.pdf. Accessed Oct 31 2012.

16. Wildhagen MF, Verheij JB, Verzijl JG, et al. Cost of care of patients with cystic fibrosis in The Netherlands in 1990-1. Thorax. 1996;51:298-301. Erratum in: Thorax 1997;52:204.

17. Johnson JA, Connolly M, Jacobs P, et al. Cost of care for individuals with cystic fibrosis in Alberta: a regression approach to determining important cost drivers [working paper 99-2] Edmonton (AB): Institute of Health Economics. 1996:1-29.

18. Ireys HT, Anderson GF, Shaffer TJ, Neff JM. Expenditures for care of children with chronic illnesses enrolled in the Washington State Medicaid program, fiscal year 1993. Pediatrics. 1997;100:197-204.
19. Johnson JA, Connolly MA, Jacobs P, Montgomery $\mathrm{M}$, Brown NE, Zuberbuhler P. Cost of care for individuals with cystic fibrosis: a regression approach to determining the impact of recombinant human DNase. Pharmacotherapy. 1999;19:1159-66.

20. Lieu TA, Ray GT, Farmer G, et al. The cost of medical care for patients with cystic fibrosis in a health maintenance organization. Pediatrics. 1999;103:e72.

21. Wildhagen MF, Verheij JB, Verzijl JG, et al. The nonhospital costs of care of patients with CF in the Netherlands: results of a questionnaire. Eur Respir J. 1996;9:2215-9.

22. Briesacher BA, Quittner AL, Fouayzi H, Zhang J, Swensen A. Nationwide trends in the medical care costs of privately insured patients with cystic fibrosis (CF), 2001-2007. Pediatr Pulmonol. 2011;46:770-6.

23. Koopmanschap MA. Cost-of-illness studies. Useful for health policy? Pharmacoeconomics. 1998;14:143-8.

24. Liou TG, Adler FR, Fitzsimmons SC, Cahill BC, Hibbs JR, Marshall BC. Predictive 5-year survivorship model of cystic fibrosis. Am J Epidemiol. 2001;153:345-52.

25. Buzzetti R, Alicandro G, Minicucci L, et al. Validation of a predictive survival model in Italian patients with cystic fibrosis. J Cyst Fibros. 2012;11:24-9.

26. Legge 548/93 "Disposizioni per la prevenzione e la cura della Fibrosi Cistica" [GU 30/12/1993, n³05]. Available at: www.medicoeleggi.com. Accessed Oct 312012.

27. Horvais V, Touzet S, Francois S, et al. Cost of home and hospital care for patients with cystic fibrosis followed up in two reference medical centres in France. International Journal of Technology Assessment in Health Care. 2006;22:525-31.

28. Padman R, McColley SA, Miller DP, et al. Infant care patterns at epidemiologic study of cystic fibrosis sites that achieve superior childhood lung function. Pediatrics. 2007;119:e531-7.

29. Eidt-Koch D, Wagner TO, Mittendorf T, Graf von der Schulenburg JM. Outpatient medication costs of patients with cystic fibrosis in Germany. Appl Health Econ Health Policy. 2010;8:111-8. 
30. Dewitt EM, Grussemeyer CA, Friedman JY, et al. Resource use, costs, and utility estimates for patients with cystic fibrosis with mild impairment in lung function: analysis of data collected alongside a 48-week multicentre clinical trial. Value Health. 2012;15:277-83.
31. Ratjen F, Grasemann H. New therapies in cystic fibrosis. Curr Pharm Des. 2012;18:614-27.

32. Bush A, Simmonds NJ. Hot off the breath: 'I've a cost for' - the 64 million dollar question. Thorax. 2012;67:382-4. 